\title{
The role of patient preferences in adherence to treatment in chronic disease: a narrative review
}

\author{
Serena Losi ${ }^{1}$, Cesare Celeste Federico Berra ${ }^{2}$, Riccardo Fornengo ${ }^{3}$, Dario Pitocco ${ }^{4}$, Giovanni Biricolti ${ }^{5}$, Marco Orsini Federici ${ }^{1}$ \\ ${ }^{1}$ Eli Lilly Italy S.p.A., Sesto Fiorentino - Italy \\ ${ }^{2}$ IRCCS MultiMedica, Sesto San Giovanni, Milano - Italy \\ ${ }^{3}$ S.S.D. di Diabetologia ASL TO4, Torino - Italy \\ ${ }^{4}$ Diabetes Care Unit Fondazione Policlinico Universitario Agostino Gemelli IRCCS, Roma - Italy \\ ${ }^{5}$ Eli Lilly Italy S.p.A., Roma - Italy
}

\begin{abstract}
Adherence to prescribed medication is important to the management of all diseases, especially those of chronic nature. Drug effectiveness is substantially compromised by therapy nonadherence. We reviewed the available evidences on the impact of patient preferences for therapy on adherence to a prescribed treatment in chronic diseases requiring long-term treatment. A search on PubMed retrieved 699 publications, leading to a selection of 12 publications: 6 on osteoporosis, 2 on moderate-to-severe asthma, 1 on type 1 diabetes, 1 on type 2 diabetes, 1 on kidney transplantation, and 1 on atrial fibrillation. Overall, 8 studies found a positive association between patient preference and adherence to therapy, while the others found no association. In general, overall adherence was considered to be high in the published studies. The reasons for a positive association included reduced dosing frequency, route of administration, lower costs, and favorable safety profile, which is related to the diverse nature of the pathology and its type and duration of treatment. A literature review suggests that achieving good adherence and persistence to therapy requires evaluation of patient preferences. In a period of increasingly limited resources, more effort is warranted to promote better adherence to therapy, especially when patients must self-manage their disease in the long term. Our results further highlight that insufficient attention has been given to the relationship between patient preference and adherence and point out the complex nature of adherence and the need for adequate patient education. More efforts are also needed to better understand the entity of cost savings for payers for specific treatments and the link with patient preference.
\end{abstract}

Keywords: Adherence, Chronic disease, Preferences, Therapy

\section{Introduction}

Patient preference to any prescribed medication or therapy is assuming an increasingly important impact in achieving clinically relevant outcomes. For example, the American Diabetes Association (ADA) and the European Association for the Study of Diabetes (EASD) 2018 consensus report for type 2 diabetes emphasizes that patient choices and preferences are of utmost importance when choosing a therapy (1). Adherence to prescribed medication is important to the management of all diseases, and especially those of a chronic nature such as diabetes, dyslipidemia, and hypertension

Received: September 24, 2021

Accepted: October 20, 2021

Published online: November 08, 2021

Corresponding author:

Serena Losi

Eli Lilly Italia S.p.A.

Via A. Gramsci 731/733

50019 Sesto Fiorentino (FI) - Italy

losi_serena@lilly.com since disease-related symptoms are often absent, and because long-term drug effectiveness is substantially compromised by nonadherence to therapy. According to a report from the World Health Organization (WHO), adherence to long-term therapy is a problem of global magnitude and averages about $50 \%$ in developed countries (2). Moreover, poor adherence is associated with poorer outcomes and increased costs of care (2).

It has also been hypothesized that increasing adherence to medications may have a greater impact on a population's health than further improvements in medical therapies (3). Poor adherence decreases the effectiveness of therapy and leads to suboptimal use of resources as undertreated patients tend to develop complications and comorbidities $(4,5)$. In type 2 diabetes and hypertension, poor adherence rates may result in poorer health outcomes and increased mortality (4-8). Several studies in chronic conditions have also demonstrated that poor adherence is associated with adverse consequences in terms of risk of hospitalization and overall costs (9). For diabetes, hypercholesterolemia, and hypertension, savings in all-cause medical costs have been reported when levels of adherence are high (10). 
Lack of adherence is influenced by multiple factors that include psychological issues, polypharmacy, and ease of obtaining and administering the medication, as well as patient motivation and education (11). Several studies on patient preferences for a variety of therapies have suggested that increased patient preference for one therapy over another is likely to be associated with increased adherence to therapy $(7,11,12)$. However, only a limited number of studies have measured the potential impact of patient preferences on adherence, meaning that both dimensions have been quantified in the same study.

With mounting attention to overall costs of healthcare, increasing weight is being given to cost-effectiveness of any given treatment. Indeed, it has been suggested that patient preferences for treatment may have significant implications for cost-effectiveness by affecting not only costs but also clinical outcomes (13). The impact of adherence and its potential importance in both clinical and economic terms can be highlighted by considering data from Italy where only $31 \%$ of patients with chronic diseases refer that they are completely adherent to therapy (14). Accordingly, payers should implement cost-effectiveness models that incorporate patient preferences (13).

Based on all these considerations, we performed a literature search and narrative review with the objective of overviewing the available evidence on the impact of patient preferences for therapy on adherence to a prescribed treatment in diseases requiring long-term treatment to help improve decisionmaking processes for physicians and payers. Focus was placed on chronic diseases, since outcomes are likely to be more linked to adherence to therapy in the long term.

\section{Materials and methods}

\section{Overall strategy}

The methods, including the search strategy, were developed based on relevant literature (15-18). A narrative literature review (19) of published studies assessing compliance, adherence, or persistence and treatment preferences from 2010 (inclusive) to April 20, 2021, was conducted using the PubMed-NCBI database. The following search string was used: ("Patient Preference"[mesh] OR Preferen*[tiab]) AND (adherence[tiab] OR compliance[tiab] OR persistence[tiab] OR concordance[tiab]) AND ("Chronic Disease"[mesh] OR diabetes OR copd OR asthma OR "chronic obstructive pulmonary disease" OR hypertension OR osteoporosis OR "Chronic Disease" OR "Chronic condition") With the exception of Medical Subject Headings (MeSH) terms associated with each article, to maximize the retrieval of relevant articles, keywords were searched only within the title and abstract. To increase sensitivity, the keyword "preference" was truncated to "preferen" and followed by the special operator "*" (e.g., to catch both preference and preferential). Further truncation did not improve sensitivity and was associated with a drastic deterioration in specificity of articles retrieved. Similar tests were carried out for all the other keywords. While the search priority was the association between patient preferences and medication adherence, associations between patient preferences and clinical efficacy were included if relevant.

\section{Inclusion and exclusion criteria}

All studies that involved human subjects of any age with one or more chronic diseases were considered. Focus was given to the Centers for Disease Control and Prevention (CDC) definition of chronic disease as those lasting more than 1 year and which require ongoing medical attention, limit activities of daily living, or both (20), with the exclusion of cancer. Interventions of interest included those related to pharmacological treatment, with or without associated use of medical devices. All studies published in English language including a clear method of how patient preference and medication adherence or persistence (or efficacy) were objectively measured were included. Editorials, review articles, surveys, opinion papers, letters to the editor, case reports or case studies, study protocols, and guidelines were excluded. Publications describing adherence only, preferences only, or those mentioning only self-management behaviors, but not medication adherence, were also excluded, as were speculative articles where patient preference was not directly assessed.

Search results were imported into Microsoft Excel. Two reviewers were responsible for data extraction. A two-part study selection process was used: title and abstract review followed by full-text review. In the first step, two reviewers separately review the title and abstract of citations from the search to determine the eligibility based on the inclusion and exclusion criteria. All articles considered relevant by either reviewer were included in the full-text evaluation where the two reviewers independently evaluated the full-text articles to determine if they met inclusion/exclusion criteria. In case of disagreement about inclusion, full-text articles were reviewed again by both reviewers and if agreement was not reached, this was resolved by consultation with an independent third reviewer. As this is a narrative review, no statistical analyses were performed.

\section{Results}

The initial literature search on PubMed retrieved 699 publications. Despite the structured query, the majority of extracted papers were not relevant to the topic of interest.

Analysis led to a selection of 12 publications. Overall, 275 papers were excluded because they did not consider patients' treatment or device preferences or a specific chronic disease involved; 265 due to article type (e.g., review/editorial); 71 investigated only dietary patterns, exercise, or nonpharmacological devices (e.g., mandibular advancement device or mobile apps); 56 because they explored only patient preferences without quantitative measurements of actual adherence; 12 investigated the treatment decision-making style adopted and not an actual preference for treatment; 6 because adherence of one treatment option was not assessed or close to $100 \%$ by study design (e.g., a single injection performed at study enrollment), making pointless any possible comparison with other treatments considered; and 2 because they were related to a study already included (two publications by Kendler $(21,22)$ were excluded as they refer to the one by Freemantle with final results of the study (23) which was included).

The selected studies, listed in Table I, included 6 papers on osteoporosis, 2 on moderate-to-severe asthma, 1 on type 
TABLE I - Studies included on patient preference and adherence to therapy

\begin{tabular}{|c|c|c|c|c|c|}
\hline Author & Disease & Main aim & Study design & No. patients & Main finding \\
\hline $\begin{array}{l}\text { Eliasaf et al. } \\
2016(25)\end{array}$ & Osteoporosis & $\begin{array}{l}\text { Determine compliance } \\
\text { and persistence with } \\
\text { osteoporosis therapy among } \\
\text { postmenopausal women and } \\
\text { to assess attitudes regarding } \\
\text { treatment resumption among } \\
\text { patients on drug holiday. }\end{array}$ & $\begin{array}{l}\text { Prospective } \\
\text { observational } \\
\text { study }\end{array}$ & 150 & $\begin{array}{l}\text { Compliance was high overall } \\
(80 \%) \text {; there was not a preferred } \\
\text { medication among patients on } \\
\text { drug holiday. }\end{array}$ \\
\hline $\begin{array}{l}\text { Freemantle } \\
\text { et al. } 2012 \\
(23)\end{array}$ & Osteoporosis & $\begin{array}{l}\text { Compare treatment adherence } \\
\text { between subcutaneous } \\
\text { denosumab every } 6 \text { months } \\
\text { and oral alendronate once } \\
\text { weekly. }\end{array}$ & $\begin{array}{l}\text { 2-year, } \\
\text { randomized, } \\
\text { crossover study }\end{array}$ & 250 & $\begin{array}{l}\text { Of } 198 \text { subjects expressing } \\
\text { treatment preference, } 92.4 \% \\
\text { preferred injectable denosumab } \\
\text { over oral alendronate. } \\
\text { Denosumab was associated } \\
\text { with less nonadherence than } \\
\text { alendronate (first year, } 11.9 \% \\
\text { vs. } 23.4 \% \text {; second year, } 7.5 \% \text { vs. } \\
36.5 \% \text { ). }\end{array}$ \\
\hline $\begin{array}{l}\text { Jarab et al. } \\
2020 \text { (24) }\end{array}$ & Osteoporosis & $\begin{array}{l}\text { Explore factors associated with } \\
\text { medication nonadherence in } \\
\text { Jordan. }\end{array}$ & Observational & 296 & $\begin{array}{l}72.3 \% \text { were nonadherent; } \\
\text { patients were less likely to adhere } \\
\text { to the prescribed medications } \\
\text { with each unit increase in } \\
\text { the number of prescribed } \\
\text { medications and if they did not } \\
\text { have a trust in the efficacy of the } \\
\text { medications. }\end{array}$ \\
\hline $\begin{array}{l}\text { Oral et al. } \\
2015(27)\end{array}$ & Osteoporosis & $\begin{array}{l}\text { Examine the level of } \\
\text { compliance and persistence in } \\
\text { patients with postmenopausal } \\
\text { osteoporosis receiving daily } \\
\text { risedronate with either fixed } \\
\text { dosing of three different timing } \\
\text { regimens (A: before breakfast; } \\
\text { B: in-between meals; C: before } \\
\text { bedtime) or with flexible } \\
\text { dosing. }\end{array}$ & $\begin{array}{l}\text { Randomized, } \\
\text { crossover study }\end{array}$ & 448 & $\begin{array}{l}49.7 \% \text { preferred flexible and } \\
50.3 \% \text { fixed timing; a significant } \\
\text { difference between the flexible } \\
\text { and fixed regimens was seen in } \\
\text { persistence in favor of the flexible } \\
\text { regimen. Persistence was defined } \\
\text { as the continuation of treatment } \\
\text { at Week } 26 \text {. }\end{array}$ \\
\hline $\begin{array}{l}\text { Sakai et al. } \\
2014 \text { (26) }\end{array}$ & Osteoporosis & $\begin{array}{l}\text { Evaluate the effects of } \\
\text { once-monthly minodronate } \\
\text { on treatment persistence } \\
\text { and clinical parameters } \\
\text { in outpatients previously } \\
\text { treated with daily or weekly } \\
\text { bisphosphonate products. }\end{array}$ & $\begin{array}{l}\text { Multicenter, } \\
\text { prospective, } \\
\text { open-label, } \\
\text { observational } \\
\text { study }\end{array}$ & $\begin{array}{l}264 \text { and } 133 \\
\text { patients were } \\
\text { allocated into } \\
\text { the Switch and } \\
\text { Continue groups } \\
\text { (continue daily or } \\
\text { weekly bisphos- } \\
\text { phonates). }\end{array}$ & $\begin{array}{l}\text { Approximately } 65 \% \text { of } \\
\text { patients were willing to switch } \\
\text { to minodronate, with the } \\
\text { predominant reason being } \\
\text { "less frequent dosing more } \\
\text { convenient." Treatment } \\
\text { persistence was significantly } \\
\text { higher in the Switch group. } \\
\text { Persistence was assessed through } \\
\text { Kaplan-Meier curves and analyzed } \\
\text { using the log-rank test. }\end{array}$ \\
\hline $\begin{array}{l}\text { Thomasius } \\
\text { et al. } 2016 \\
\text { (28) }\end{array}$ & Osteoporosis & $\begin{array}{l}\text { Compared the preference, } \\
\text { acceptability, and tolerability } \\
\text { of a reformulation of Calcichew } \\
\text { D31 } 500 \mathrm{mg} / 400 \mathrm{IU} \text { and } \\
\text { Calcichew D3 } 500 \mathrm{mg} / 800 \mathrm{IU} \\
\text { with Adcal-D32 } 500 \mathrm{mg} / 400 \mathrm{IU} \\
\text { and Kalcipos-D } 500 \mathrm{mg} / 800 \mathrm{IU} \text {. }\end{array}$ & $\begin{array}{l}\text { Phase IV, } \\
\text { randomized, } \\
\text { open-label, } \\
\text { two-period, } \\
\text { cross-over } \\
\text { study }\end{array}$ & 276 & $\begin{array}{l}\text { Patients preferred Calcichew } \\
\text { D3 500/400 and Calcichew D3 } \\
500 / 800 \text { over comparators as it is } \\
\text { significantly less chalky and sticky, } \\
\text { and is easier to chew and swallow. } \\
\text { Acceptability did not affect } \\
\text { compliance. }\end{array}$ \\
\hline $\begin{array}{l}\text { Al Hayek } \\
\text { et al. } 2020 \\
\text { (31) }\end{array}$ & $\begin{array}{l}\text { Type } 1 \\
\text { diabetes }\end{array}$ & $\begin{array}{l}\text { Compare preferences and } \\
\text { adherence for } 6-\mathrm{mm} \text { and } \\
8-\mathrm{mm} \text { injection needles. }\end{array}$ & $\begin{array}{l}\text { Prospective } \\
\text { cohort study }\end{array}$ & 62 & $\begin{array}{l}\text { 6-mm needles were associated } \\
\text { with lower pain score, higher } \\
\text { patient adherence, greater } \\
\text { patient satisfaction, and better } \\
\text { glycemic control compared to } \\
\text { 8-mm needles. }\end{array}$ \\
\hline
\end{tabular}


TABLE I - (Continued)

\begin{tabular}{|c|c|c|c|c|c|}
\hline Author & Disease & Main aim & Study design & No. patients & Main finding \\
\hline $\begin{array}{l}\text { Ishii et al. } \\
2018 \text { (32) }\end{array}$ & $\begin{array}{l}\text { Type } 2 \\
\text { diabetes }\end{array}$ & $\begin{array}{l}\text { Compare the treatment } \\
\text { satisfaction of four classes of } \\
\text { oral agents: DPP-4 inhibitors, } \\
\alpha \text {-glucosidase inhibitors, } \\
\text { biguanides, and sulfonylureas. }\end{array}$ & $\begin{array}{l}\text { 12-week, } \\
\text { randomized, } \\
\text { controlled, } \\
\text { open-label } \\
\text { study }\end{array}$ & 64 & $\begin{array}{l}\text { DPP- } 4 \text { inhibitor was the most } \\
\text { preferable option in terms of } \\
\text { treatment satisfaction and had } \\
\text { the highest adherence. }\end{array}$ \\
\hline $\begin{array}{l}\text { Plaza et al. } \\
2018 \text { (29) }\end{array}$ & $\begin{array}{l}\text { Moderate to } \\
\text { severe asthma }\end{array}$ & $\begin{array}{l}\text { Assess the impact of patient } \\
\text { satisfaction with an inhaler } \\
\text { on adherence and health } \\
\text { outcomes. }\end{array}$ & $\begin{array}{l}\text { Cross- } \\
\text { sectional, } \\
\text { observational, } \\
\text { multicenter } \\
\text { study }\end{array}$ & 778 & $\begin{array}{l}\text { High specific satisfaction with } \\
\text { an inhaler was associated with } \\
\text { younger age, male gender, } \\
\text { controlled asthma, high general } \\
\text { satisfaction with treatment, high } \\
\text { adherence to inhaler, nonsevere } \\
\text { asthma, and no trouble with } \\
\text { inhaler use. }\end{array}$ \\
\hline $\begin{array}{l}\text { Valero et al. } \\
2019(30)\end{array}$ & $\begin{array}{l}\text { Moderate to } \\
\text { severe asthma }\end{array}$ & $\begin{array}{l}\text { Compare patient satisfaction } \\
\text { of three dry powder inhalers. }\end{array}$ & $\begin{array}{l}\text { Register of an } \\
\text { observational, } \\
\text { multicenter } \\
\text { study }\end{array}$ & 328 & $\begin{array}{l}\text { Specific satisfaction with inhaler } \\
\text { was significantly higher with } \\
\text { Easyhaler'T, as well as the }_{\text {percentage of patients with }} \\
\text { high satisfaction with inhaler. } \\
\text { Scores for Easyhaler }{ }^{\mathrm{TM}} \text { were also } \\
\text { significantly better for items such } \\
\text { as learning how to use, inhaler } \\
\text { preparation, inhaler use, weight } \\
\text { and size, and portability. There } \\
\text { were no significant differences } \\
\text { in asthma control or adherence } \\
\text { between inhalers. }\end{array}$ \\
\hline $\begin{array}{l}\text { Wu et al. } \\
2019 \text { (33) }\end{array}$ & $\begin{array}{l}\text { Atrial } \\
\text { fibrillation }\end{array}$ & $\begin{array}{l}\text { Compare persistence and } \\
\text { outcomes of non-vitamin K } \\
\text { antagonist oral anticoagulants } \\
\text { (NOACs) vs. warfarin. }\end{array}$ & $\begin{array}{l}\text { Prospective } \\
\text { cohort study }\end{array}$ & 344 & $\begin{array}{l}\text { Persistence with anticoagulants } \\
\text { was low and dropped sharply } \\
\text { at the third month; patients on } \\
\text { NOACs had worse persistence at } \\
3,6 \text {, and } 12 \text { months than those } \\
\text { on warfarin; the main reason } \\
\text { for anticoagulant cessation was } \\
\text { patient preference (adverse } \\
\text { events, costs). }\end{array}$ \\
\hline $\begin{array}{l}\text { Hugo et al. } \\
2021 \text { (34) }\end{array}$ & $\begin{array}{l}\text { Kidney } \\
\text { transplantation }\end{array}$ & $\begin{array}{l}\text { Evaluate conversion from } \\
\text { immediate-release tacrolimus } \\
\text { (IR-T) to prolonged-release } \\
\text { tacrolimus (PR-T) in stable } \\
\text { kidney transplant recipients. }\end{array}$ & $\begin{array}{l}\text { 12-month, non- } \\
\text { interventional } \\
\text { study }\end{array}$ & 183 & $\begin{array}{l}\text { Among patients reporting a } \\
\text { preference, } 78.4 \% \text { preferred PR-T. } \\
\text { Following conversion from IR-T } \\
\text { to PR-T adherence was high and } \\
\text { kidney function was stable over } \\
12 \text { months. }\end{array}$ \\
\hline
\end{tabular}

1 diabetes, 1 on type 2 diabetes, 1 on atrial fibrillation, and 1 in patients with a stable kidney transplant. Overall, 6 studies found a positive association between patient preference and adherence to therapy, while the others found no association.

In general, overall adherence was considered to be high in the published studies. An exception was the study by Jarab et al in which $72 \%$ of patients were nonadherent; patients were less likely to adhere to therapy with each increase in the number of medications and when they did not trust the efficacy (24). In the study by Eliasaf et al, $80 \%$ of patients took their medication as directed (64\% were on an oral medication, mostly bisphosphonates). However, in comparing treatments for osteoporosis, there was no preferred medication among patients on drug holiday (25). Freemantle carried out a 2-year randomized, crossover trial comparing subcutaneous denosumab every 6 months to oral alendronate once weekly, and reported that denosumab was associated with less nonadherence than alendronate in both years of the trial (first year, $11.9 \%$ vs. $23.4 \%$; second year, $7.5 \%$ vs. $36.5 \%$ ) (23). This greater adherence to denosumab was likely related to the greater preference with injections every 6 months rather than an oral drug weekly. In considering dosing frequency, Sakai et al similarly reported that more patients were willing to switch to a weekly bisphosphonate, rather than continuing to receive daily administration, with the predominate reason that less frequent dosing is more convenient. Furthermore, they observed that treatment persistence was significantly higher in the Switch group than the Continue group $(89.8 \%$ 
vs. 78.9\%; $p<0.003)(26)$. Oral et al compared flexible to fixed dosing regimens in women receiving daily risedronate (27). While there was no difference in preference of the two regimens, a significant difference was seen, with treatment persistence favoring the flexible regimen. Lastly, the trial by Thomasius compared preferences of a reformulated vitamin $\mathrm{D} /$ calcium supplement (28). While patients preferred a formulation that was less chalky and sticky, and easier to chew and swallow, acceptability had no effect on compliance.

Two of the remaining studies investigated the use of inhalers in patients with moderate to severe asthma. The trial by Plaza et al found that high patient satisfaction with an inhaler, independently of the medication contained within, was associated with better adherence and, accordingly, better control of asthma (29). As in the study by Valero et al, patients preferred an inhaler that was easy to use and easy to learn to use (30).

The study in type 1 diabetes by Al Hayek et al evaluated 6-mm vs. 8-mm injection needles in terms of adherence, satisfaction, and glycemic control (31). It was reported that the narrower needle was associated with greater satisfaction, better adherence, and improved glycemic control compared to the high-gauge needle. The trial by Ishii et al examined treatment satisfaction of commonly used oral treatments, reporting that DPP-4 inhibitors were preferred over $\alpha$-glucosidase inhibitors, biguanides, or sulfonylureas (32). DPP-4 inhibitors were also associated with better adherence to therapy vs. $\alpha$-glucosidase inhibitors, biguanides, or sulfonylureas (93\%, $87 \%, 64 \%$, and $62 \%$, respectively). The authors concluded that the higher treatment satisfaction of patients can motivate therapeutic adherence, likely resulting in better glycemic control (32). Wu et al compared persistence and outcomes of non-vitamin $\mathrm{K}$ antagonist oral anticoagulants (NOACs) to warfarin. Patients on NOACs were seen to have worse persistence at 3, 6, and 12 months than those on warfarin; the main reasons for anticoagulant discontinuation cited were related to patient preference such as adverse bleeding events and costs (33).

Lastly, Hugo et al examined the effects of converting patients with a stable kidney graft from immediate-release tacrolimus (IR-T) to prolonged-release tacrolimus (PR-T) (34). Over a period of 12 months, there was no change in renal function, adherence was high; $98 \%$ of patients referred that they were satisfied or very satisfied with the therapy, while 78\% preferred PR-T.

\section{Discussion}

Herein, we performed a literature search yielding 12 publications in order to overview the available investigations on patient preferences and adherence to therapy for chronic diseases. Of note, there were more studies on osteoporosis $(n=6)$ compared to other chronic diseases, although this may possibly be explained that during the time of these studies more costly injection therapies were beginning to replace more consolidated treatments. The majority (8/12) of the studies in the present review reported a positive association between patient preference and adherence to therapy. The reasons for a positive association included reduced dosing frequency, route and means of administration, lower costs, and a more favorable safety profile. These factors may be related to the diverse nature of the pathology and its treatment.

Four of the studies did not report a direct association between patient preference and adherence to treatment, although this can likely be explained by factors related to the individual study. Considering the studies on osteoporosis, that by Eliasaf et al reported that their study included highly motivated patients, that compliance was higher than that previously reported in the literature, and that patients on drug holiday did not have a preference for medication (25). All these factors may have had a role in the lack of significant differences. The trial by Thomasius et al found that while patients clearly had a preferred formulation, acceptability did not influence compliance to therapy (28). This result could be attributed to the short-term nature of that study, which followed patients for only 30 days. Oral et al, instead, observed no difference in preference of the two regimens, and thus an association between preference and adherence cannot be assessed (31).

Moreover, regarding the two studies on inhaler preference for moderate to severe asthma, the study by Plaza et al found a positive association between inhaler satisfaction with adherence, while that by Valero et al found no such association $(29,30)$. However, those authors commented that due to the sample size in the subanalysis performed, the difference in patient satisfaction was not adequate to properly reflect differences in adherence and control of asthma.

In the trial included in the present analysis on type 2 diabetes, DPP-4 inhibitors were considered to provide greater satisfaction with treatment, possibly because of the less frequent dosing and less concern over adverse events compared to other treatments; such factors likely motivate patients to better adherence to therapy and lead to superior glycemic control (32). Moreover, since drug reimbursements were not completely covered by the healthcare system in which the study was carried out, the cost of DPP-4 inhibitors appeared to be a concern for some patients since management of type 2 diabetes is lifelong, thus highlighting the important role of patient preference for therapy (32). Another recent study in patients with type 2 diabetes on oral treatment showed that the vast majority still prefer a daily oral simple therapy, but the second choice was for weekly injection with a ready to use device (35). In the study included in type 1 diabetes on needle preferences, a smaller gauge needle was associated with greater satisfaction in terms of injection comfort and pain as well as greater overall satisfaction. These preferences led not only to greater adherence to therapy but also to significantly fewer hypoglycemic episodes per month and to significantly lower glycated hemoglobin (7.9\% vs. $8.3 \%$ ) (31).

In the study on atrial fibrillation by Wu et al, persistence to therapy with anticoagulants was strongly influenced by costs, as well as with adverse events to treatment (33). Indeed, patients prescribed NOACs had worse persistence than those given warfarin and the study was carried out in China where, as noted by the authors, NOACs are approximately 80 times more expensive than warfarin, which influences not only preference, but the ability to acquire the drug. In that 
investigation, there was no difference in adverse events between NOACs and warfarin.

Among the studies on osteoporosis, Freemantle et al reported greater adherence and preference with a single subcutaneous injection every 6 months vs. an oral treatment once weekly (23). Moreover, patients crossing over to weekly oral therapy had poorer adherence after the switch, suggesting a treatment sequence effect. The differences in adherence and preference are likely to be related to multiple factors such as frequency of administration, belief in the need for and efficacy of individual therapies, and duration of treatment. The impact of different dosing regimens in osteoporosis was explored by Oral et al who reported that while there was no actual preference for a fixed or flexible dosing regimen, the latter was associated with significantly higher persistence to therapy (27). Overall persistence levels with flexible dosing were $86.0 \%$ compared to $78.9 \%$ with a fixed regimen. It was speculated that alternate timing for administration of therapy might aid patients with difficulty following traditional before-breakfast dosing, thus offering an additional option that can be more easily incorporated into diverse lifestyles and needs. The importance of timing and frequency of administration can be further highlighted in the study by Hugo et al in kidney transplant patients who preferred prolonged-release tacrolimus over an immediaterelease formulation (34). Moreover, PR-T was also easier to remember that IR-T, with the main reasons cited for preferring the prolonged-release formulation being no need to take it in the evening and reduced pill burden.

In the study by Jarab et al carried out in Jordan on osteoporosis, adherence was dismal, and $72 \%$ of women were nonadherent to therapy (24). Similarly low rates of adherence in osteoporosis were also reported in a study from the US where nonadherents were $70 \%$ at 1 year, and $84 \%$ at 3 years (36). Increased number of medications was a primary reason for nonadherence in the study by Jarab et al, although it should be mentioned that patients were taking an average of five medications, three of which were for osteoporosis. This highlights the need to simplify the overall therapeutic regimen. The study also reported that lack of trust in efficacy was a major motivator for nonadherence, which stresses the need for patient education and establish a good physicianpatient relationship.

The manifestation of medical and psychological complications of any disease worsens the quality of life and leads to inefficient use of resources. Taken together, the consequences of poor adherence compromise the possibility that a healthcare system can fulfill the needs of patients. The problem of adherence to therapy occurs whenever self-administration of the treatment is required, regardless of the type and severity of the illness and the possibility of access to treatment. While the problem may seem simple, poor adherence is multifactorial and is related to factors related to the patient, its treatment, and the disease $(2,11)$. For example, patients with diabetes generally have other comorbidities such as hypertension, obesity, and depression, which may contribute to a less than adequate response to therapy (37). Costs also increase 2.2-3.2 times when the patient develops micro- and macrovascular complications that could be prevented (38).
The costs of hospitalization, which include treatment of longterm complications such as heart disease, can account for more than $50 \%$ of total costs (38). Thus, economic and social benefits will become substantial only if the healthcare system can achieve a greater level of efficiency in promoting adherence to self-management of chronic disease. The ongoing challenge is demonstrated from a study in Italy, wherein $45 \%$ of patients with a chronic disease indicated that they did not understand their disease and were not able to self-manage it; only $31 \%$ declared that they were completely adherent to therapy and over $50 \%$ of patients said they had thought about abandoning care for their disease (14).

This suggests that in order to achieve good adherence and persistence, evaluation of patient preferences is a crucial step. A study conducted in Italy on preference toward different therapeutic options in injection-naïve and -non-naïve patients with type 2 diabetes clearly showed preference for simple oral therapies and with a low risk of side effects to therapy in injection-naïve subjects (39). The situation dramatically changed in patients who had already experienced injection therapy, who preferred that their therapy be administered with a ready to use device over the possibility of going back to oral therapy. Moreover, when considering all the different therapeutic attributes, among all patients the most preferred option was for a weekly injectable therapy with a ready to use device, while the first oral daily therapy ranked fifth (39).

The WHO has classified barriers to adherence into five dimensions: healthcare team/system, therapy, condition, patient, and socioeconomic-related barriers (2). Better understanding of the barriers to adherence is needed to overcome them and increase therapeutic outcomes in chronic disease. In the past, less emphasis was placed on adherence, but this paradigm seems to have been gradually changing over the years; this may be related to the aging population and increased prevalence of chronic disease. Considering other dimensions of the WHO classification, individual patient characteristics such as age and level of education may be related to adherence, in addition to factors such as costs depending on the specific setting. Thus, despite the somewhat limited evidence to date, it should be assumed that patient preference has an impact on adherence.

The present analysis has some limitations. Firstly, we considered only a single database and it is possible that additional studies were not retrieved from the literature search. Secondly, the inclusion criteria were very strict, with the result that only a small number of publications were included. Lastly, four studies included considered patient satisfaction as a proxy for preference. Although a higher satisfaction among treatments will likely result in a preference, this was not directly assessed in those cases.

\section{Conclusion}

Our results highlight that insufficient attention has been given to studying the direct relationship between patient preference and adherence, but seem to confirm its existence. It is hoped that this review can serve as a stimulus for further research in this little explored area, which could 
help to better understand patient needs and desires, with the overarching aim of improving adherence to treatment in chronic diseases, understand the impact on total costs of treatment, and therefore achieve better outcomes. This review also stresses the complex nature of adherence, and the need for adequate patient education so that they understand the benefits of therapy for their particular condition. Costs are undoubtedly important when considering any treatment for a chronic disease, and more efforts are needed to better understand the entity of cost savings for payers for specific treatments and the link with patient preference. If a patient prefers a certain treatment over another, adherence is likely to increase along with better allocation of resources.

\section{Acknowledgments}

Matteo Mucchetti and Patrick Moore provided writing and editorial assistance for this manuscript on behalf of Health Publishing \& Services Srl.

\section{Disclosure}

Dr. C. C. Berra in 2019 participated in scientific boards sponsored by: Eli Lilly, Astra Zeneca, Novo Nordisk, Boehringer, Mundipharma, Sanofi; conduced clinical studies sponsored by: Eli Lilly, Novo Nordisk, Sofar; and participated in sponsored lectures at national conferences by: Boehringer, Eli Lilly, Sanofi, Novo Nordisk.

Dr. Riccardo Fornengo declares that the research was conducted in the absence of any commercial or financial relationships that could be construed as a potential conflict of interest.

Prof. D. Pitocco declares no conflict of interest.

Marco Orsini Federici, Serena Losi and Giovanni Biricolti are employees of Eli Lilly Italia SpA and minor stockholders at Eli Lilly \& Company.

\section{References}

1. Davies MJ, D'Alessio DA, Fradkin J, et al. Management of hyperglycemia in type 2 diabetes, 2018. A consensus report by the American Diabetes Association (ADA) and the European Association for the Study of Diabetes (EASD). Diabetes Care. 2018;41(12):2669-2701. CrossRef PubMed

2. World Health Organization. Adherence to long-term therapies: evidence for action. Online. Accessed 7 July 7, 2020.

3. Haynes RB, McDonald H, Garg AX, Montague P. Interventions for helping patients to follow prescriptions for medications. Cochrane Database Syst Rev. 2002;(2):CD000011. PubMed

4. Egede LE, Gebregziabher M, Echols C, Lynch CP. Longitudinal effects of medication nonadherence on glycemic control. Ann Pharmacother. 2014;48(5):562-570. CrossRef PubMed

5. Martin LR, Williams SL, Haskard KB, Dimatteo MR. The challenge of patient adherence. Ther Clin Risk Manag. 2005;1(3):189-199. PubMed

6. Cramer JA. A systematic review of adherence with medications for diabetes. Diabetes Care. 2004;27(5):1218-1224. CrossRef PubMed

7. Ferdinand KC, Yadav K, Nasser SA, et al. Disparities in hypertension and cardiovascular disease in blacks: the critical role of medication adherence. J Clin Hypertens (Greenwich). 2017;19(10): 1015-1024. CrossRef PubMed

8. Ho PM, Rumsfeld JS, Masoudi FA, et al. Effect of medication nonadherence on hospitalization and mortality among patients with diabetes mellitus. Arch Intern Med. 2006;166(17): 1836-1841. CrossRef PubMed
9. Boye KS, Curtis SE, Lage MJ, Garcia-Perez LE. Associations between adherence and outcomes among older, type 2 diabetes patients: evidence from a Medicare Supplemental database. Patient Prefer Adherence. 2016;10:1573-1581. CrossRef PubMed

10. Sokol MC, McGuigan KA, Verbrugge RR, Epstein RS. Impact of medication adherence on hospitalization risk and healthcare cost. Med Care. 2005;43(6):521-530. CrossRef PubMed

11. Tiktin M, Celik S, Berard L. Understanding adherence to medications in type 2 diabetes care and clinical trials to overcome barriers: a narrative review. Curr Med Res Opin. 2016;32(2):277-287. CrossRef PubMed

12. Gelhorn HL, Sexton CC, Classi PM. Patient preferences for treatment of major depressive disorder and the impact on health outcomes: a systematic review. Prim Care Companion CNS Disord. 2011;13(5):PCC.11r01161. CrossRef PubMed

13. Brazier JE, Dixon S, Ratcliffe J. The role of patient preferences in cost-effectiveness analysis: a conflict of values? PharmacoEconomics. 2009;27(9):705-712. CrossRef PubMed

14. Gentile S, Strollo F. Aderenza e semplicità: quale ruolo nella terapia con GLP1-RA. Collana Editoriale Associazione Medici Diabetologi. Online. Accessed November 10, 2020.

15. Green BN, Johnson CD, Adams A. Writing narrative literature reviews for peer-reviewed journals: secrets of the trade. J Chiropr Med. 2006;5(3):101-117. CrossRef PubMed

16. Ledade SD, Jain SN, Darji AA, Gupta VH. Narrative writing: effective ways and best practices. Perspect Clin Res. 2017;8(2): 58-62. CrossRef PubMed

17. Pautasso M. Ten simple rules for writing a literature review. PLOS Comput Biol. 2013;9(7):e1003149. CrossRef PubMed

18. van Hoorn R, Kievit W, Booth A, et al. The development of PubMed search strategies for patient preferences for treatment outcomes. BMC Med Res Methodol. 2016;16(1):88. CrossRef PubMed

19. Siddaway AP, Wood AM, Hedges LV. How to do a systematic review: a best practice guide for conducting and reporting narrative reviews, meta-analyses, and meta-syntheses. Annu Rev Psychol. 2019;70(1):747-770. CrossRef PubMed

20. Centers for Disease Control and Prevention. About Chronic Diseases. Online. Accessed November 10, 2020.

21. Kendler DL, Macarios D, Lillestol MJ, et al. Influence of patient perceptions and preferences for osteoporosis medication on adherence behavior in the Denosumab Adherence Preference Satisfaction study. Menopause. 2014;21(1):25-32. CrossRef PubMed

22. Kendler DL, McClung MR, Freemantle N, et al; DAPS Investigators. Adherence, preference, and satisfaction of postmenopausal women taking denosumab or alendronate. Osteoporos Int. 2011;22(6):1725-1735. CrossRef PubMed

23. Freemantle N, Satram-Hoang S, Tang ET, et al; DAPS Investigators. Final results of the DAPS (Denosumab Adherence Preference Satisfaction) study: a 24-month, randomized, crossover comparison with alendronate in postmenopausal women. Osteoporos Int. 2012;23(1):317-326. CrossRef PubMed

24. Jarab AS, Mukattash TL, Hilan H. Medication non-adherence in patients with osteoporosis: implications for clinical pharmacists and osteoporosis care providers. Curr Clin Pharmacol. 2020;15(3):243-250. CrossRef PubMed

25. Eliasaf A, Amitai A, Maram Edry M, Yosselson Superstine $S$, Rotman Pikielny P. Compliance, persistence, and preferences regarding osteoporosis treatment during active therapy or drug holiday. J Clin Pharmacol. 2016;56(11):1416-1422. CrossRef PubMed

26. Sakai $\mathrm{A}$, Ikeda $\mathrm{S}$, Okimoto $\mathrm{N}$, et al. Clinical efficacy and treatment persistence of monthly minodronate for osteoporotic patients unsatisfied with, and shifted from, daily or weekly 
bisphosphonates: the BP-MUSASHI study. Osteoporos Int. 2014;25(9):2245-2253. CrossRef PubMed

27. Oral A, Lorenc R; FLINT-ACT Study Investigators. Compliance, persistence, and preference outcomes of postmenopausal osteoporotic women receiving a flexible or fixed regimen of daily risedronate: a multicenter, prospective, parallel group study. Acta Orthop Traumatol Turc. 2015;49(1):67-74. CrossRef PubMed

28. Thomasius F, Keung Nip T, Ivan P. Phase IV randomized preference study in patients eligible for calcium and vitamin $D$ supplementation. Curr Med Res Opin. 2016;32(10):1623-1631. CrossRef PubMed

29. Plaza V, Giner J, Calle M, et al. Impact of patient satisfaction with his or her inhaler on adherence and asthma control. Allergy Asthma Proc. 2018;39(6):437-444. CrossRef PubMed

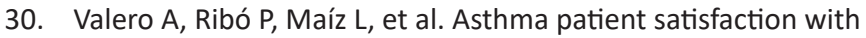
different dry powder inhalers. Expert Rev Respir Med. 2019; 13(2):133-138. CrossRef PubMed

31. Al Hayek AA, Al Dawish M. Evaluating the user preference and level of insulin self-administration adherence in young patients with type 1 diabetes: experience with two insulin pen needle lengths. Cureus. 2020;12(6):e8673. CrossRef PubMed

32. Ishii H, Hayashino Y, Akai Y, Yabuta M, Tsujii S. Dipeptidyl peptidase-4 inhibitors as preferable oral hypoglycemic agents in terms of treatment satisfaction: results from a multicenter, 12-week, open label, randomized controlled study in Japan (PREFERENCE 4 study). J Diabetes Investig. 2018;9(1):137-145. CrossRef PubMed

33. $\mathrm{Wu} \mathrm{S}, \mathrm{Xie} \mathrm{S}, \mathrm{Xu} \mathrm{Y}$, et al. Persistence and outcomes of nonvitamin $\mathrm{K}$ antagonist oral anticoagulants versus warfarin in patients with non-valvular atrial fibrillation. J Clin Nurs. 2019; 28(9-10):1839-1846. CrossRef PubMed

34. Hugo C, Weihprecht $\mathrm{H}$, Banas B, et al. Renal function and patient-reported outcomes in stable kidney transplant patients following conversion from twice-daily immediate-release tacrolimus to once-daily prolonged-release tacrolimus: a 12-month observational study in routine clinical practice in Germany (ADAGIO). Transplant Proc. 2021;53(5):1484-1493. CrossRef PubMed

35. Boye K, Ross M, Mody R, Konig M, Gelhorn H. Patients' preferences for once-daily oral versus once-weekly injectable diabetes medications: the REVISE study. Diabetes Obes Metab. 2021;23(2):508-519. CrossRef PubMed

36. Weycker D, Macarios D, Edelsberg J, Oster G. Compliance with drug therapy for postmenopausal osteoporosis. Osteoporos Int. 2006;17(11):1645-1652. CrossRef PubMed

37. Ciechanowski PS, Katon WJ, Russo JE. Depression and diabetes: impact of depressive symptoms on adherence, function, and costs. Arch Intern Med. 2000;160(21):3278-3285. CrossRef PubMed

38. Bruno G, Picariello R, Petrelli A, et al. Direct costs in diabetic and non diabetic people: the population-based Turin study, Italy. Nutr Metab Cardiovasc Dis. 2012;22(8):684-690. CrossRef PubMed

39. Marchesini G, Pasqualetti P, Anichini R, et al. Patient preferences for treatment in type 2 diabetes: the Italian discretechoice experiment analysis. Acta Diabetol. 2019;56(3):289-299. CrossRef PubMed 